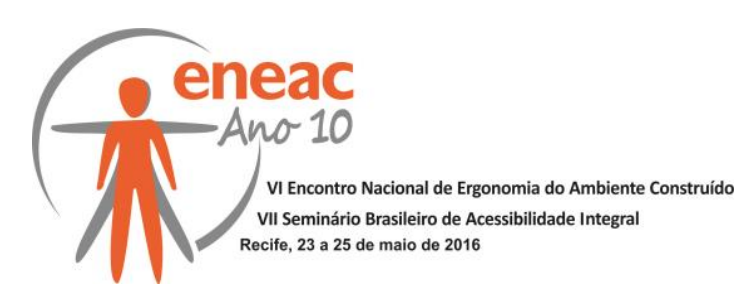

\title{
AVALIAÇÃO PÓS-OCUPAÇÃO DE PROJETO PADRÃO PROINFÂNCIA: UMA ABORDAGEM MULTIMÉTODOS NO CMEI - ESPAÇO DA INFÂNCIA
}

\author{
NATALINO, Maria Luiza Rodrigues (1); \\ ÁVILA, Vinícius Martins (2) \\ (1) Centro Universitário do Leste de Minas Gerais, Arquiteta e Urbanista \\ e-mail: malu.rodrigues.92@gmail.com \\ (2) Universidade Federal de Minas Gerais, Especialista em Construção Civil \\ e-mail: vnc.avila@gmail.com
}

\begin{abstract}
RESUMO
Este artigo consiste no relato do estudo de caso do Espaço da Infância, projeto padrão Proinfância, em Coronel Fabriciano, Minas Gerais. Pretende-se enfatizar a avaliação de aspectos comportamentais através de análise crítica dos métodos, Vistoria, Passeio Walkthrough, Mapa Comportamental, Desenho Temático e Poema dos Desejos. Explicitando a relevância da seleção de métodos adequados para mapear percepções dos usuários, descrevendo as dinâmicas de aplicação dessas técnicas, comparando-as e indicando tecnologias para auxiliar a Avaliação Pós-Ocupação (APO). Entende-se que a difusão de experiências em APO contribui para produções nessa área e estimula a atuação de profissionais e estudantes de arquitetura e urbanismo.
\end{abstract}

Palavras chave: Avaliação Pós-Ocupação; Métodos; Educação; Tecnologia.

\begin{abstract}
This article consists on the report of the case study of CMEI - Espaço da Infância, Prolnfância standard project, located in Coronel Fabriciano, Minas Gerais. This work aims to emphasize the evaluation of behavioral aspects, through a critical analysis of methods: the Inspection, the Walkthrough, the Behavioral Map, the Thematic Drawing and the Wish Poem. It is explained the relevance of the selection of appropriate methods to map the perceptions of the users, describing the applications dynamics of the selected techniques, comparing those applications and providing technologies to assist the Post-Occupational Evaluation (POE). It is understood that the diffusion of experiences presente at the POE, contributes to works in this field and stimulates architecture and urbanism professionals and students.
\end{abstract}

Keywords: Post-Occupational Evaluations; Methods; Education; Technologies.

\section{INTRODUÇÃO}

No Brasil o projeto padrão para escolas públicas surge em busca da racionalização construtiva, e também como recurso político, que torna a atuação pública mais nítida nas cidades. Estes projetos são utilizados como modelos a serem repetidos, mas deveriam ser adequados aos diferentes locais onde serão implantados. A racionalização age contra os 


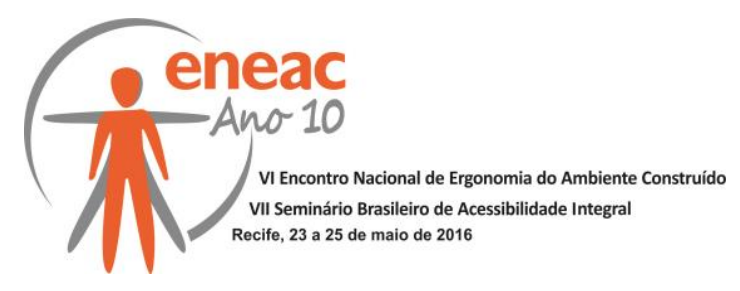

desperdícios, de tempo e materiais, e a favor da funcionalidade, utilizando de um raciocínio sistemático. Para ROSSO (1980) a padronização é uma alternativa de dar algo a todos, em vez de tudo a alguém, mas deixa o usuário a cargo de futuras adaptações. A avaliação nos equipamentos que utilizam projeto padrão deve acontecer constantemente para não haver uma proliferação de problemas construtivos, funcionais e de conforto ambiental. BARROS e KOWALTOWSKI (2002, p.251) indicam como os problemas nas edificações devem ser enfrentados e como avaliá-las. "Na detecção de problemas deverá haver mecanismos para o aprimoramento contínuo. Recomenda-se a aplicação de métodos e técnicas de APO, considerando tanto o ponto de vista dos técnicos, bem como a aferição dos níveis de satisfação dos usuários e medições relativas a conforto ambiental em todos seus aspectos."

O equipamento escolar que utiliza de projeto padrão a ser analisado neste artigo foi produzido através do Programa Nacional de Reestruturação e Aquisição de Equipamentos para a Rede Escolar Pública de Educação Infantil (Proinfância), instituído pela Resolução federal no 6, de 24 de abril de 2007, BRASIL (2007). O Proinfância surgiu de uma solicitação do Fundo Nacional de Desenvolvimento da Educação (FNDE) ao Laboratório de Projetos do Departamento de Engenharia Civil e Ambiental da Universidade de Brasília (LabProjetos). Esse projeto presta assistência técnica e transfere recursos financeiros a municípios para construir creches e adquirir equipamentos e mobiliários para a educação infantil. A cargo dos municípios ficam os gastos relativos à titularidade do terreno e à infraestrutura necessária para implantação dos projetos. Os projetos padrão do FNDE (2015) são nomeados pelo mesmo como tipo "B", para lotes com dimensões de 40x70m e tipo "C" $45 \times 35 \mathrm{~m}$, os projetos possuem algumas alterações devido ao número de alunos que a escola, voltada à educação infantil de crianças de 0 a 5 anos, beneficiará. Possuindo demanda mínima de 240 alunos, ou 120 em tempo integral, para concorrer ao projeto tipo "B" e 120 alunos, ou 60 em tempo integral, para concorrer ao projeto tipo "C", com base em dados do Censo Escolar. Os projetos elaborados pelos proponentes são nomeados projetos tipo "A" e não há limite de atendimento, nem dimensões mínimas exigidas para o terreno.

Embora esses projetos de acordo com o FNDE tenham sido desenvolvidos considerando a diversidade brasileira, o Tribunal de Contas da União (TCU) em uma auditória operacional, realizada em 2012, realçou diversas fragilidades do projeto e do programa. Fragilidades inclusive relativas aos diferentes aspectos bioclimáticos no país, características específicas que o projeto padrão não era capaz de se adequar. Foi notado também que diversos espaços nas escolas construídas através do Proinfância são subutilizados, o que pode ser justificado pela falta de identificação com as características culturais regionais. O TCU (2012) constatou que "não houve um diagnóstico amplo, estruturado e prévio que embasasse a concepção dos projetos arquitetônicos definidos como padrão para o programa.". Os projetos padrão passaram por pequenas alterações e atualmente contemplam algumas das adaptações sugeridas. Entretanto ainda existem inúmeras especificidades locais que são desconsideradas e ocasionam em edificações com problemas relativos ao conforto ambiental, que não expressam a identidade das comunidades e que geram altos custos relativos à sua implantação para as prefeituras.

No início do processo educativo, etapa que o ser humano é notadamente suscetível às influências do meio, o espaço físico da escola deve ser compreendido como parte relevante no desenvolvimento humano. A atenção para a denominada primeira infância é de grande importância. "De fato, os sete primeiros anos de vida de uma pessoa comportam um intenso processo de desenvolvimento físico, afetivo, cognitivo e social. Os mestres na área demonstram que, [...] aos 7 anos a criança já tem as bases de sua personalidade delineadas e efetuou grande parte de seu aprendizado total." (ELALI, 2002, p.1) A grande interferência que o ambiente escolar tem na vida dos alunos que os frequentam é potencializada quando as crianças possuem idades inferiores aos 7 anos e também quando a escola adere a um programa de educação integral. A pedagogia, o espaço e o tempo escolar são elementos significantes na construção dos indivíduos, logo, da sociedade. Um ambiente para educação 


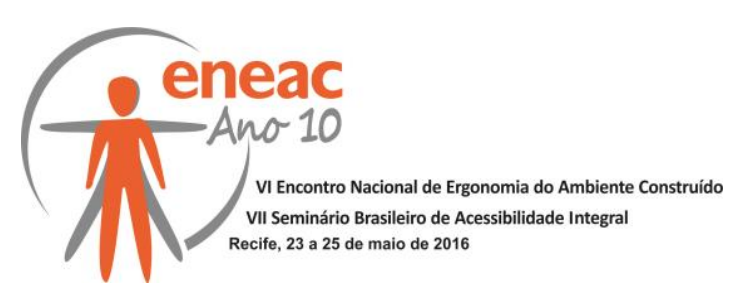

infantil em tempo integral deve então propiciar muito mais do que conhecimento acadêmico, deve incluir em seu currículo escolar práticas, habilidades, costumes, crenças e valores que introduzam essas crianças à vida em sociedade.

A Avaliação Pós-Ocupação (APO) é um método que surgiu buscando relacionar o ambiente construído ao indivíduo e ao seu comportamento, avaliando assim o desempenho destes ambientes. Para ELALI (2002, p.135) este método é essencial no processo de produção arquitetônico, pois reabastece o ciclo projetual, quando "terminado o ciclo programa/projeto/execução, o prédio passa a cumprir sua função de abrigar o ser humano em suas inúmeras atividades.". ORNSTEIN (1992) descreve objetivos deste tipo de metodologia, de avaliação de desempenho de ambiente construído, são eles, propor ações ou intervenções que contribuam para a qualidade de vida dos usuários do espaço avaliado e produzir um banco de informações que geram conhecimento na área avaliada. No campo das ciências sociais as pesquisas avaliativas tem o propósito de tornar eficiente qualquer intervenção humana e aperfeiçoar as condições sociais e comunitárias, logo se tornam atividades políticas. "[...] quaisquer que sejam os resultados da avaliação, as descobertas decorrentes serão consideradas como boas para alguns e más para outros. Afinal de contas, avaliar é fazer julgamentos, ou realizar uma avaliação é prover descobertas/diagnósticos que podem ser utilizados para se realizar julgamentos." (ROSSI e FREEMAN, 1989, p.372)

O MEC reconhece a necessidade da avaliação de políticas e de programas de educação infantil, porém responsabiliza as Secretarias Municipais e Estaduais de Educação a avaliarem o papel do Estado em relação aos direitos, às obrigações e às garantias das crianças a uma Educação Infantil de qualidade. "Implantar, até o segundo ano de vigência deste PNE, avaliação da educação infantil, a ser realizada a cada 2 (dois) anos, com base em parâmetros nacionais de qualidade, a fim de aferir a infraestrutura física, o quadro de pessoal, as condições de gestão, os recursos pedagógicos, a situação de acessibilidade, entre outros indicadores relevantes;" (PNE, 2014). Porém falta na maioria das prefeituras, principalmente nos municípios de pequeno porte, profissionais aptos a realizar esta avaliação de forma sistêmica, especialmente por falta de referências específicas, que poderiam ser disponibilizadas por órgãos federais.

De acordo com CAU (2013) são áreas de atuação especificadas como privativas dos arquitetos e urbanistas "relatório técnico de arquitetura referente a memorial descritivo, caderno de especificações e de encargos e Avaliação Pós-Ocupação", em anexo à esta resolução em um glossário o significado da APO é descrito como "atividade técnica que, consistindo na avaliação do resultado de projeto materializado através de obra ou serviço técnico, tem por objetivo diagnosticar aspectos positivos e negativos do ambiente construído em uso." Deparar com a APO dentre as atribuições exclusivas dos arquitetos e urbanista evidencia a importância de pesquisas nesta área, ainda com pouca atuação destes profissionais.

\section{OBJETIVO}

Este artigo possui objetivo de relatar a experiência de uma APO multimétodos no Centro Municipal de Educação Infantil (CMEI) Espaço da Infância e analisar quatro métodos utilizados, Passeio walkthrough, Mapa Comportamental, Desenho Temático e Poema dos Desejos. Espera-se, a partir de uma análise das dinâmicas de aplicação dos métodos selecionados, ressaltar as facilidades e dificuldades de suas aplicabilidades e indicar tecnologias que poderiam servir como instrumentos para auxiliar futuras avaliações de ambientes construídos voltados à educação infantil. 


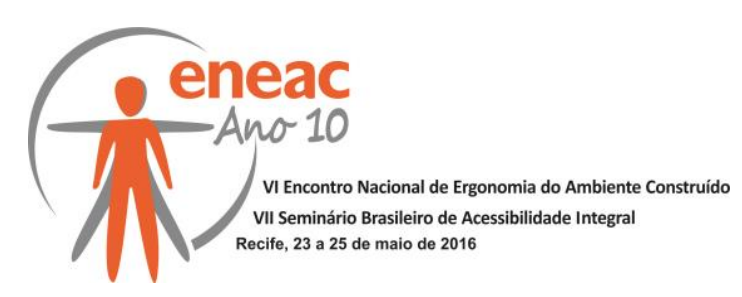

\section{APRESENTAÇÃO DOS MÉTODOS SELECIONADOS PARA APO NO CMEI}

Ao analisar criticamente o sistema público que constrói equipamentos escolares utilizando projetos padrão, decidiu-se realizar uma APO, no CMEI - Espaço da Infância, uma escola infantil municipal em Coronel Fabriciano, Vale do Aço, Minas Gerais. O CMEl utilizou o projeto padrão tipo "B" do Próinfância, projeto que foi replicado inúmeras vezes para construir equipamentos escolares em contextos urbanos e culturais distintos em todo território nacional. Em busca de uma avaliação que consiga captar a percepção dos usuários sobre o ambiente construído e entender de que maneira este ambiente estimula ou restringe as atividades que abriga, percebeu-se necessário à aplicação de diferentes métodos/técnicas para a realização da APO. "Dados provenientes de uma única fonte são passíveis de dúvida, sendo aconselhável contrabalançar os desvios surgidos a partir de uma coleta de dados oriundos de outros métodos a fim de minimizar as distorções no resultado final do trabalho." (MARANS e SPRECHELMEYER, 1987, p.83)

Para a escolha de quais métodos seriam eficientes para uma avaliação voltada aos usuários dos equipamentos escolares, percebeu-se prudente seguir a recomendação de BECHTEL (1989), através de uma revisão bibliográfica e de um contato inicial com o objeto de estudo e com seus usuários torna-se mais fácil decidir quais técnicas se adéquam as avaliações a serem realizadas pelos pesquisadores. Após a revisão bibliográfica decidiu-se embasar a APO multimétodos nas produções acadêmicas de ELALI (2002) e RHEINGANTZ et al. (2009). No primeiro contato com a escola, foi iniciada a Vistoria no CMEI, este método consiste no levantamento, através de pesquisa e entrevistas semiestruturadas, de informações relativas ao equipamento escolar a ser a avaliado. Segundo ELALI (2002) os seis aspectos básicos que devem ser investigados são: caracterização da instituição, identificação dos usuários, proposta projetual, ocupação do lote e sua inserção na malha urbana, aspectos complementares (segurança e questões relativas ao conforto na edificação) e documentação do levantamento. Durante a realização da vistoria no equipamento escolar foi observado as diferentes idades, comportamentos e características sociais dos usuários, alunos, professores, funcionários, pais e responsáveis, partindo dessa disparidade e a fim de estabelecer eficientes formas de comunicação entre a pesquisadora e os usuários optou-se pelos seguintes métodos aplicados após a vistoria nesta ordem, Passeio Walkthrough, Mapa Comportamental, Desenho Temático e Poema dos Desejos.

O segundo método aplicado na APO do equipamento escolar foi o Passeio Walkthrough, uma técnica criada por LYNCH (1960) para estudos da Psicologia Ambiental que combina observação com uma entrevista. Descrito por RHEINGANTZ et al. (2009) como "percurso dialogado complementado por fotografias, croquis gerais e gravação de áudio e de vídeo, abrangendo todos os ambientes", é através deste passeio que o pesquisador conhece toda a edificação a ser avaliada durante o seu uso e obtém descrições dos aspectos positivos e negativos percebidos pelo próprio usuário. O Mapa Comportamental é um instrumento, também originado na Psicologia Ambiental, que registra graficamente as atividades realizadas pelos usuários no ambiente avaliado. Esta técnica segundo RHEINGANTZ et al. (2009, p.13) possibilita "identificar os usos, os arranjos espaciais, os fluxos e as relações espaciais observados" além de "indicar as interações, os movimentos e a distribuição das pessoas em um determinado ambiente." Para a observação acontecer de forma eficiente se torna necessário observar os comportamentos dos usuários durante diferentes atividades cotidianas na escola, como a entrada/saída das crianças, período de aulas e recreio. Segundo SOMMER e SOMMER (1997) existem dois tipos de mapas comportamentais para APO, os mapas centrados nos indivíduos e os mapas centrados nos lugares.

Para uma abordagem direta aos usuários crianças, em APO realizadas em escolas, ELALI (2002, p.150) indica como método apropriado o Desenho Temático, criado para "pesquisas na área de representações sociais". Este método, conhecido por TRINCA (1976) como 


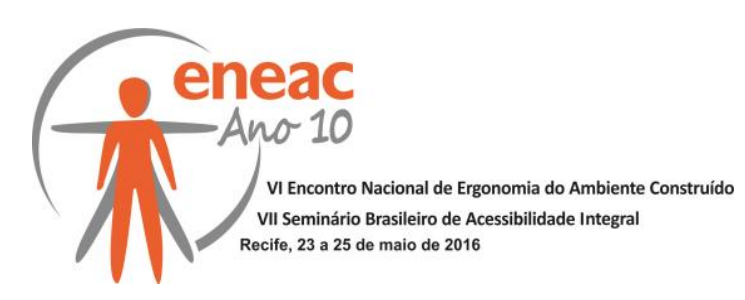

desenho-estória-com-tema, é aplicado através de uma pergunta elaborada de maneira lúdica pelo pesquisador que seja de fácil compreensão para a criança e a estimule a participar, segundo AIELLO-VAISBERG (1997, p.267-268) "O pesquisador brinca ao perguntar, substituindo questões conceituais por uma espécie de enigma imaginário, ao qual o sujeito só pode responder brincando.". O instrumento Poema dos Desejos foi selecionado a fim de avaliar o ponto de vista dos usuários adultos do equipamento escolar. Este método foi proposto por SANOFF (1991) em busca de acessar aspectos cognitivos dos usuários que foram obtidos a partir de suas experiências no lugar. Sendo o poema desejos um instrumento não estruturado e espontâneo tornasse mais fácil alcançar declarações dos sentimentos, necessidades, aspirações e desejos dos usuários para com o ambiente avaliado. "O poema dos desejos (Wish Poems) foi desenvolvido [...] para principalmente conhecer o sentimento global expresso pela comunidade de acordo com a necessidade do ambiente em questão, sendo eficaz no conhecimento dos valores e necessidades humanas de cada usuário no projeto de arquitetura." (PÁSCOA, 2008, p.73) Os participantes, através de desenhos e sentenças escritas, relatam suas opiniões em fichas padronizadas a partir da continuidade da seguinte frase previamente escrita no cabeçalho da folha "Eu gostaria que o meu [edifício/ambiente]..." embaixo da frase é deixado um espaço para livre expressão dos respondentes.

\section{APO: RELATO DA EXPERIENCIA NO CMEI - EPAÇO DA INFANCIA}

\subsection{Dinâmica de aplicação dos métodos}

Paralelamente ao processo de revisão bibliográfica, que possibilitou a seleção dos métodos a serem aplicados na APO no CMEI, foram realizadas três reuniões com profissionais das áreas de Educação, Arquitetura e Urbanismo e Engenharia Civil da Prefeitura de Coronel Fabriciano, município onde esta escola é localizada. Nessas reuniões buscou-se apreender o conhecimento destes profissionais advindos principalmente das experiências vivenciadas pelos mesmos nos cargos públicos que ocupam e estabelecer uma relação que possibilitasse o desenvolvimento da APO, a partir do reconhecimento da relevância da pesquisa realizada e da necessidade de intervenção no atual sistema federal de construção de equipamentos escolares. Posteriormente ao processo de revisão bibliográfica e de reuniões com profissionais da Prefeitura de Coronel Fabriciano, iniciou-se a APO com foco em aspectos comportamentais a partir dos métodos selecionados. A metodologia construída demandou de quatorze visitas ao equipamento escolar a ser avaliado. Embora algumas observações correspondentes a um método tenham sido percebidas durante a aplicação de outro método, decidiu-se explicar como a avaliação foi realizada descrevendo a que informações e atividades a pesquisadora se propunha a buscar e realizar a cada visita, porém todas as observações foram analisadas e agregadas ao relatório de APO. Dessa forma tornou-se possível mensurar o número de visitas necessárias para realização desse processo de avaliação.

Para a realização da Vistoria foram necessárias quatro visitas, a primeira visita ocorreu no bairro Sílvio Pereira I onde foram mapeados os equipamentos e as ruas no entorno da edificação, a ocupação do lote e sua inserção na malha urbana. A segunda visita já aconteceu na escola, onde foi iniciada uma conversa com representantes do CMEI, diretora e coordenadora, através deste diálogo foram examinadas informações para caracterização da instituição e identificação dos usuários, observada a relação da escola com a comunidade e os meios de transporte utilizados pelos alunos. Na terceira visita com o projeto tipo "B" utilizado para a construção do Espaço da Infância em mãos foi mapeada a proposta projetual, como o programa do CMEl se distribui no projeto padrão, as áreas 


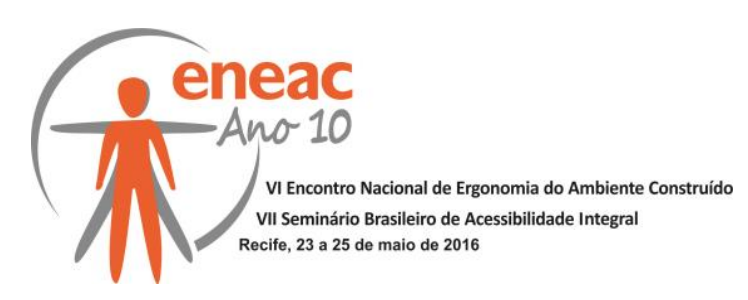

insuficientes, subutilizadas, modificadas ou acrescidas. Na quarta visita se vistoriou a implantação segundo parâmetros urbanísticos e o potencial construtivo do lote, foram também mapeados alguns aspectos complementares como segurança e questões relativas ao conforto na edificação. Durante as quatro visitas a avaliadora teve que realizar uma pesquisa sobre a região onde o $\mathrm{CMEl}$ é localizado, entrevistar usuários, utilizar de mapas do google maps e de mapas disponibilizados pela Prefeitura de Coronel Fabriciano, obter os projetos "Tipo B" disponibilizadas pelo Proinfância e os aprovados no município, produzir um estudo embasado pelas legislações locais, realizar registros fotográficos e sonoros com smartphone e utilizar de carta solar específica.

Normalmente o Passeio Walkthrough é aplicado com grupos de usuários, porém visando interferir minimamente nas atividades dos próprios usuários foi optado por realizá-lo com uma funcionária que possui cargo pedagógico, a coordenadora do $\mathrm{CMEl}$, que conhece todas as dependências da escola, tem contato direto com todos os funcionários e livre acesso a todos os ambientes. Para que o passeio acontecesse de forma dinâmica, durante a apresentação da funcionária apenas o áudio foi gravado, utilizando de um smartphone, já em um segundo momento, após o percurso, a pesquisadora retornou aos ambientes visitados para produzir registros fotográficos dos pontos destacados, utilizando o mesmo aparelho celular e fones de ouvido para acompanhar os relatos gravados. O passeio acompanhado durou aproximadamente 25 minutos, nos quais a funcionária guiou a visita e a avaliadora interferiu minimamente apenas para sanar dúvidas a respeito do que era descrito. Essa quinta visita foi determinante no desenvolvimento da APO, pois ao percorrer todo o equipamento escolar, entrando de sala em sala, acompanhada pela coordenadora do $\mathrm{CMEl}$, foi possível conhecer, além de todo o espaço construído, todos os profissionais que atuam nessa escola e as relações estabelecidas por eles com esses ambientes.

Durante o processo de produção do Mapa Comportamental julgou-se necessário mesclar os dois tipos mapas, os centrados nos indivíduos e os centrados nos lugares. Do primeiro tipo de mapa seguiu-se a recomendação de passar por um período de impregnação, para que os usuários acostumassem com a presença da pesquisadora, neste período o observador passa um tempo no ambiente avaliado sem realizar registros, apenas observando. Porém como as atividades dos vários grupos/turmas aconteciam concomitantemente, para conseguir gerar um mapa comportamental que dispusesse de informações de todos os usuários, foi preciso que além de acompanhar cada grupo de forma dinâmica, que a avaliadora seguisse em alguns momentos uma recomendação para aplicação dos mapas centrados nos lugares. Observando a partir de um ponto estratégico na escola, que não interferisse no uso cotidiano do ambiente. Deste modo, a pesquisadora pôde acompanhar como os diversos grupos se comportam, como interagem, que atividades realizam e como ocupam o espaço avaliado. Ao longo da sexta a décima visita a avaliação foi programada para contemplar todo o horário de funcionamento do CMEI durante dias comuns, das sete às dezesseis horas, abrangendo os horários de entrada e saída dos alunos, todas as refeições, os momentos de socialização e recreação, os períodos de atividades dentro das salas de aula, as oficinas/ateliês e as horas do banho e do sono. Para registrar o que era mapeado foi necessário dispor de plantas da escola, produzir croquis, realizar anotações descrevendo as ações, as turmas que as realizavam e em quais horários e utilizar de um smartphone para gravar áudios e produzir fotografias e vídeos.

Na décima primeira e décima segunda visita percebeu-se necessário realizar o Desenho Temático juntamente com uma entrevista, devido à faixa etária dos alunos nas escolas do Próinfância, 0 a 5 anos, facilitando a concentração da criança na atividade proposta e a análise dos desenhos produzidos. Se esta análise for realizada posteriormente pela pesquisadora a interpretação do trabalho poderia se tornar muito subjetiva e não absorver relevantes aspectos tratados pelos usuários. Em conversa com a diretora, a coordenadora e professoras da escola foram selecionadas as turmas que poderiam mais facilmente contribuir com a avaliação. As turmas do primeiro período foram indicadas, crianças entre 4 


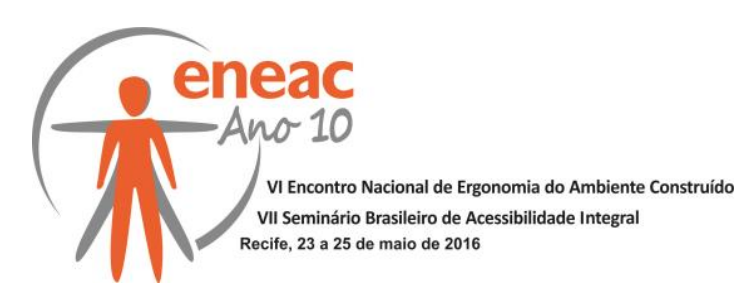

e 5 anos, por possuírem linguagem gráfica e verbal mais desenvolvidas que a dos alunos mais novos. Para realização dos desenhos foram disponibilizados para as crianças das duas turmas folhas de papel sulfite A4 branco $75 \mathrm{~g} / \mathrm{m}^{2}$ e lápis de cor sextavado 36 cores. Após colocar os materiais na frente de cada aluno a pesquisadora os orientou, de forma lúdica, a desenhar as atividades que gostam de fazer na escola e em quais ambientem as realizam, 20 crianças das turmas A e B participaram.

Durante as visitas percebeu-se inviável aplicar o método Poema dos Desejos durante o horário de funcionamento da escola, devido à necessidade de cuidados e estímulos constantes das crianças na faixa etária atendida pelo CMEI. Em conjunto com a coordenadora da escola, a fim de não atrapalhar os dias letivos, decidiu-se pedir que os funcionários contribuíssem ao processo de avaliação, realizando o método fora de seus horários de trabalho. Na décima terceira visita foram entregues aos funcionários as fichas com a frase "Eu gostaria que o meu CMEI..." os possíveis participantes foram orientados a respondê-las de forma livre, através de textos, expressões, palavras ou desenhos. Após o prazo de uma semana estabelecido junto à coordenadora do $\mathrm{CMEI}$, voltou-se a escola, décima quarta visita, para buscar os registros realizados pelos funcionários. Dos 40 funcionários da escola apenas 9 devolveram as fichas preenchidas, sendo cinco educadores infantil, um monitor de apoio à criança com deficiência, uma coordenadora da escola e outros dois respondentes que não se identificaram.

\subsection{Análise comparativa das aplicações dos métodos adotados}

O planejamento da APO, escolha dos métodos a serem adotados e preparação dos instrumentos necessários foram feitos através da bibliografia disponível, especialmente contribuições do Grupo Prolugar/PROARQ/UFRJ, e das reuniões realizadas com profissionais das áreas de Educação, Arquitetura e Urbanismo e Engenharia Civil da Prefeitura de Coronel Fabriciano. A documentação de todas as visitas foi realizada através de representação escrita e gráfica à mão além do auxílio de um Smartphone Samsung Galaxy Gran Prime para a produção de registros fotográficos e gravação de áudios e vídeos.

Ao realizar as primeiras visitas ao CMEI, foi diagnosticada a impossibilidade de aplicar os métodos selecionados de maneira totalmente distanciada dos usuários, principalmente das crianças, onde a interação ocorre de maneira muito espontânea. Embora não possa ser desconsiderado que para algumas técnicas um afastamento da pesquisadora é importante, a fim de interferir minimamente nas atividades ocorridas no ambiente. Seguindo a recomendação de RHEINGANTZ et al. (2009, p.11) optou-se por aplicar os métodos selecionados a partir de uma abordagem experiencial, onde a atenção e percepção do observador "se volta, principalmente, para o entendimento das razões, nuanças e significados da experiência vivenciada no cotidiano de um determinado ambiente em uso". Consequentemente a APO foi realizada sob a prática da observação incorporada, que não nega a utilidade dos instrumentos, mas os aplica de maneira diferenciada, de acordo com RHEINGANTZ et al. (2009, p.107) torna-se necessário que o pesquisador "seja capaz de equilibrar os sentidos e as emoções, o racional e o emocional, na tentativa de não se deixar levar por impressões pré-concebidas, vagas, desatentas ou superficiais sobre o ambiente.".

Os cinco métodos aplicados neste estudo de caso, além de exigirem aplicações diferenciadas foram selecionados por contemplarem objetivos distintos. Acredita-se que uma análise comportamental é necessária a realização de uma APO multimétodos, a fim de englobar as percepções e as relações dos diferentes grupos de usuários e o conhecimento técnico do pesquisador. Através do processo de avaliação percebeu-se que as diferentes metodologias aplicadas causaram diferentes reações nos usuários. Algumas vezes pelas diferentes posturas adotadas pela avaliadora em cada técnica, mas também durante 0 


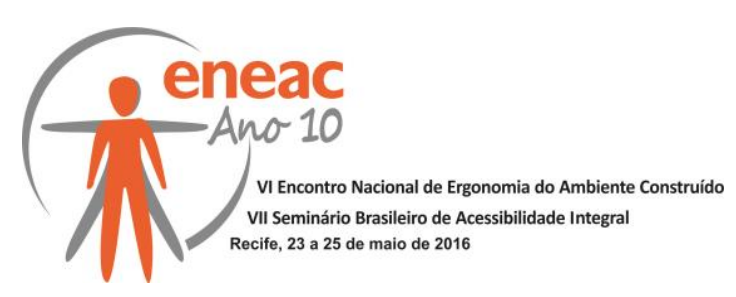

mesmo método, enquanto alguns usuários se mostraram solícitos outros se sentiram incomodados. Decidiu-se por relatar a experiência de interação entre pesquisadora e usuários, pois essa pode interferir não só nos processos, mas nos resultados da APO.

Durante a Vistoria a diretoria e coordenação do CMEI mostraram-se abertas e disponíveis. Foi observado que as crianças rapidamente se acostumam com a presença do pesquisador no ambiente escolar, sendo possível interferir minimamente no comportamento desses usuários, embora muitas vezes seja impossível evitar uma interação direta, elas são pontuais e não prejudicam a avaliação. Já para as professoras a presença de um avaliador é incômoda, para diminuir este bloqueio elas devem perceber que a APO não avalia seus desempenhos pedagógicos, mas a interação do individuo com o ambiente construído. Já ao aplicar o método Passeio Walkthrough percebeu-se que as professoras e as crianças estabeleceram sentimentos de pertencimento às salas de aula que ocupam. Esse sentimento, benéfico para os usuários, interferiu na forma com que a pesquisadora foi recebida nesses espaços, algumas vezes como um ser estranho introduzido dentro de um ambiente privado e outras vezes de forma receptiva e cordial. Devido a esses comportamentos nota-se novamente a importância de que todos os funcionários entendam o processo de avaliação que está sendo realizado. O Mapa Comportamental demandou uma postura mais observadora e afastada da pesquisadora devido a essa atitude percebeu-se um incômodo em alguns usuários adultos. Para minimizá-lo, em determinados momentos a avaliadora dialogava com esses funcionários, a fim de demonstrar interesse na relação dos usuários com o espaço construído e confirmar algumas percepções. De modo oposto, para os usuários crianças após o período de impregnação, quando eles já haviam acostumado com a presença da pesquisadora, o afastamento favoreceu o mapeamento, pois as ações praticadas pelas crianças não eram modificadas pelo processo de avaliação.

Diferente das outras técnicas já descritas, o Desenho Temático foi utilizado para uma abordagem direta aos usuários crianças. Nenhum dos alunos convidados se negou a realizar essa atividade, embora alguns tenham demonstrado maior apreço por desenhar, enquanto outros preferiam relatar suas experiências. Destaca-se que o auxilio das professoras das duas turmas selecionadas foi facilitador nos diferentes tipos de aplicações do método. Nos desenhos realizados individualmente, turma $B$, as crianças foram selecionadas pela professora por possuírem mais facilidade de representação gráfica. Já quando o método foi aplicado com um grupo de alunos na sala de aula, turma $A$, a professora auxiliou a pesquisadora na proposta da atividade às crianças e a mantê-las concentradas durante a elaboração dos desenhos. Para uma abordagem direta aos usuários adultos, funcionários, realizou-se o Poema dos Desejos. Acredita-se que a dinâmica de aplicação desse método interferiu na quantidade de respondentes, já que exigiu que realizassem a atividade em seu tempo livre, ressaltando que a maioria dos funcionários trabalha em período integral. Pelo mesmo motivo algumas respostas foram sucintas. Porém a maioria dos participantes sentiu-se a vontade para demonstrar suas insatisfações, aspirações e contentamentos com o espaço escolar construído.

\section{TECNOLOGIAS PARA AUXILIAR AS APLICAÇÕES DOS MÉtOdOS E PRODUÇÃO DA APO}

Durante a Avaliação Pós-Ocupação, desde o processo de vistoria, a aplicação dos métodos selecionados, as análises a partir de cada técnica, até a sobreposição de todas as informações obtidas, várias dificuldades foram encontradas. A cerca dessas fragilidades se destacaram as percepções de que pouco se utiliza das tecnologias existentes durante esse processo, apesar de haverem plataformas que mesmo não produzidas para esse fim poderiam assistir o desenvolvimento das APO. Por esse motivo, indicam-se para auxiliar a avaliação quatro aplicativos gratuitos, Tabela 1, disponíveis na Google Play Store, loja 


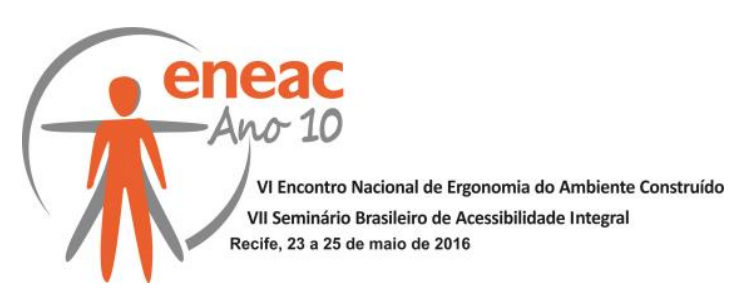

virtual do Android, onde são armazenados aplicativos destinados à plataforma. Destacam-se que de acordo com WORLDPANEL (2015) o Android é o sistema operacional mais utilizado no Brasil e que todos os aplicativos selecionados são compatíveis com o Smartphone Samsung Galaxy Gran Prime, dispositivo utilizado na APO do CMEI.

Para auxiliar a investigação e o levantamento de aspectos complementares durante a vistoria, foram selecionados dois aplicativos. O Sai Pra Lá ajuda a avaliar a segurança da área de implantação da escola. Esse aplicativo mapeia assédios às mulheres, sonoros, verbais, físicos e indefinidos, já possuindo 19 mil assédios registrados. As denúncias são de grande relevância para a avalição, uma vez que a maioria dos funcionários da escola são mulheres, grande parte dos pais e responsáveis que levam e buscam as crianças são do gênero feminino. Há diversos registros de assédios no Vale do Aço, inclusive no bairro Silvio Pereira 1, onde o CMEl é situado. Já o Sun Surveyor auxilia nas percepções de questões relativas ao conforto na edificação. O aplicativo elabora uma carta solar específica através do GPS do celular e da data de medição. É possível visualizar de forma dinâmica a trajetória do sol além de acessar a dados como latitude, longitude, posições e horas do nascer e pôr do sol, azimute e altura solar. Através da carta solar é possível perceber quais fachadas e ambientes recebem incidência solar direta durante os períodos da manhã e a da tarde, informações que aliadas a outros métodos possibilitam o entendimento da dinâmica escolar e avaliação dos problemas relativos ao conforto térmico no equipamento vistoriado.

Uma ferramenta que pode facilitar muito as aplicações dos métodos Passeio Walkthrough e Mapa Comportamental é o Google Keep. Nesse aplicativo são criadas notas que podem conter textos, fotos e áudios, ele grava mensagens de voz, e as transcreve instantaneamente. É possível ainda anexar imagens como plantas ou mapas e desenhar sobre eles. Para agrupar itens relacionados adicionam-se cores e marcadores às notas, 0 que as organiza e facilita pesquisas nas notas salvas. Assim como outras ferramentas Google, o Keep é compatível com smartphones, tablets e computadores. Logo o que é adicionado por um dispositivo ao Keep é sincronizado com todos os outros dispositivos. Durante o Passeio Walkthrough a pesquisadora pode no mesmo aplicativo, gravar o relato do usuário, marcar na planta o ambiente relatado e produzir um registro fotográfico para ilustrar o que foi dito. De modo similar no mapeamento comportamental a própria pesquisadora pode gravar notas em áudio descrevendo as atividades observadas, tirar fotos para ilustrá-las e identificar na planta em que locais as ações foram realizadas. Outro auxílio é a exibição das datas e dos horários em que todas as notas foram salvas, o que facilita analisar os dados obtidos para os dois métodos. No passeio consegue-se, desse modo, reconhecer o trajeto realizado, já no mapeamento identificam-se os horários em que cada atividade foi praticada.

Uma grande dificuldade encontrada durante a produção da APO é a organização e a seleção de fotos, necessárias para ilustrar diversas percepções sobre o espaço avaliado. Durante as visitas, no processo de avaliação do espaço construído, diversos registros são realizados, porém alguns ainda não estão associados a um método específico. Após a aplicação do Desenho Temático e do Poema dos Desejos, por exemplo, percebeu-se necessário comparar aspectos retratados pelos usuários com elementos ou ações observadas no CMEI, mas a busca em meio a tantas fotos tiradas tornou-se uma tarefa árdua. Uma plataforma que promete facilitar muito esse processo é o Google Fotos, esse aplicativo possui recursos de organização e pesquisa visuais automáticas. É possível realizar buscas por cores, elementos, objetos, temas e até por pessoas, além disso, 0 aplicativo também exibe as fotos organizadas por datas. Ambas as funções facilitam e simplificam todo o processo de elaboração de um relatório de Avaliação Pós-Ocupação. Destaca-se ainda que além dessa plataforma se sincronizar com todos os outros dispositivos configurados com a mesma conta Google, ela disponibiliza armazenamento em nuvem ilimitado, seguro e gratuito das fotos e vídeos em alta qualidade. 


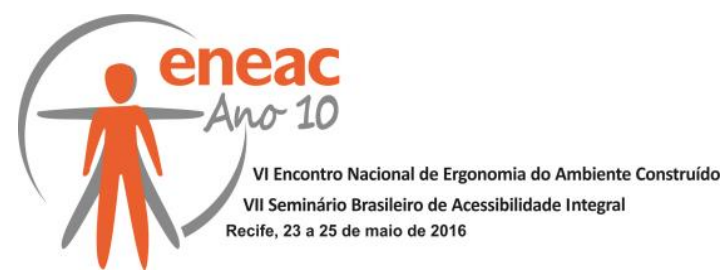

Tabela 1 - Aplicativos para auxiliar diferentes métodos da APO

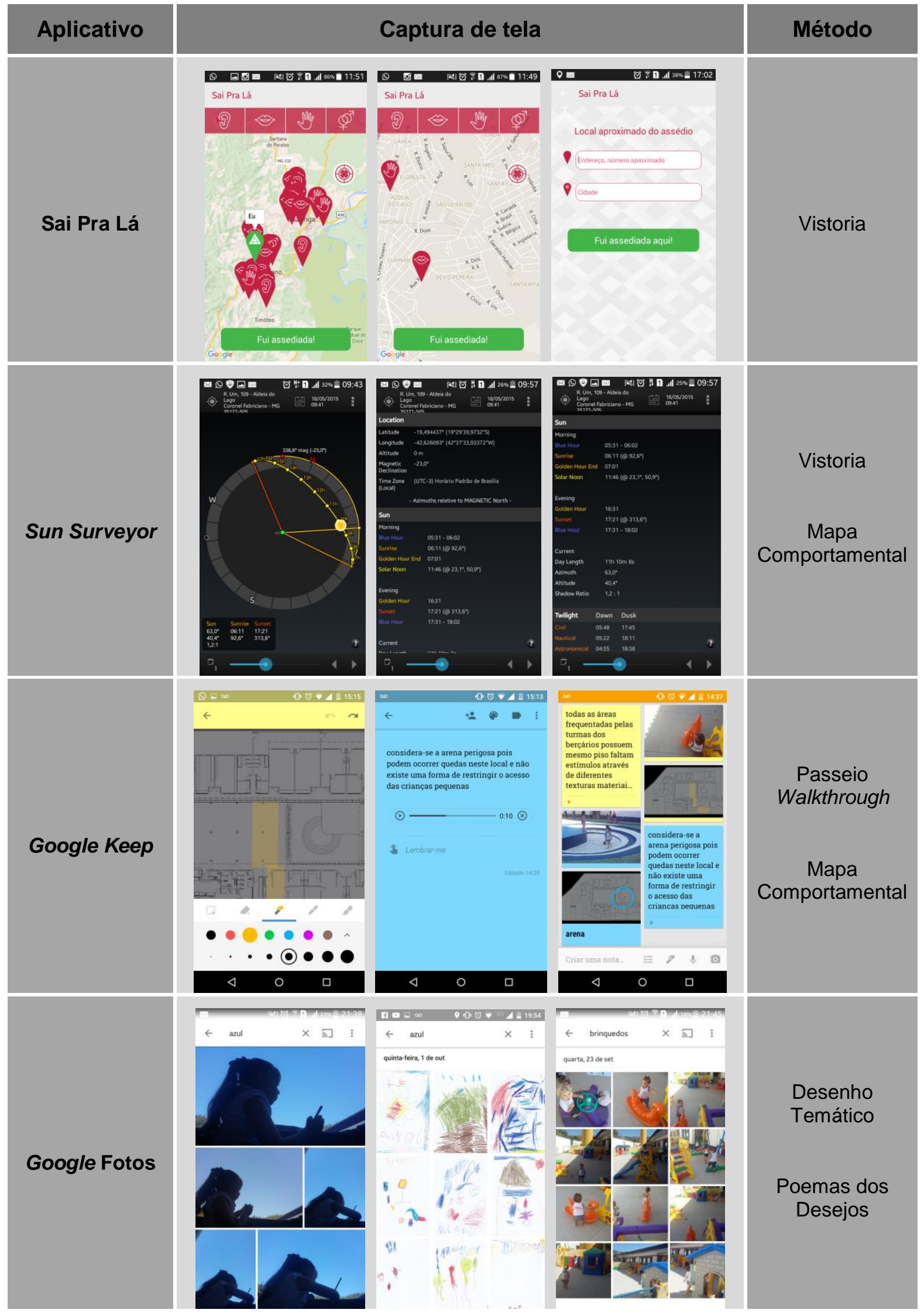

Fonte: Autores 


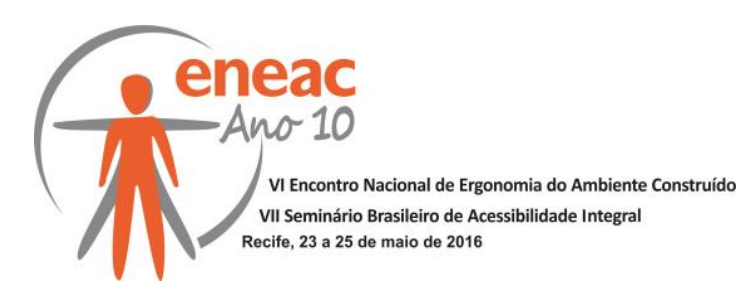

\section{CONCLUSÃO}

A análise da Avaliação Pós-ocupação evidenciou que a aplicação de multimétodos em uma APO com foco em aspectos comportamentais é fundamental para que seja possível confrontar as percepções do pesquisador com as dos diferentes grupos de usuários, crianças, orientadoras pedagógicas e demais funcionários. Deve-se então selecionar os métodos avaliando, além de seus objetivos e de suas metodologias de aplicação, quais usuários são abordados por cada técnica.

Ao aplicar os métodos selecionados, tornou-se possível averiguar as adequações necessárias na aplicação dessas técnicas e analisar que os resultados gerados por elas são suficientes para um diagnóstico coerente. As dificuldades nas aplicabilidades dos métodos estão mais relacionadas ao desconhecimento dos funcionários sobre o processo de APO e de sua função. Evidenciando a necessidade de uma reunião, com todos os funcionários, que anteceda a aplicação dos métodos. No estudo de caso do CMEI - Espaço da Infância essa apresentação inicial ocorreu apenas para a coordenadora e para a diretora da escola.

Todo o processo foi registrado com o objetivo de fornecer material que respalde futuras avaliações semelhantes, considerando que as informações fornecidas pelos usuários devem possuir papel relevante no processo de projeto de intervenções, reformas ou ampliações da edificação por eles utilizada e até mesmo no projeto de novos equipamentos similares. Acredita-se que o relatório de APO entregue a escola avaliada e à prefeitura de Coronel Fabriciano é capaz de embasar o apontamento de diretrizes e a concepção de projetos para reformas e melhorias futuras na escola avaliada e também para novos equipamentos escolares no município. Atividades que também são incluídos nas áreas de atuação dos arquitetos e urbanistas.

A partir de uma análise das dinâmicas de aplicação dos métodos selecionados, ressaltaramse facilidades e dificuldades de suas aplicabilidades. Após essa experiência, indicaram-se tecnologias que podem servir como instrumentos para auxiliar futuras avaliações de ambientes construídos voltados à educação infantil. Notou-se através de pesquisa bibliográfica a ausência de uma ferramenta específica com finalidade de amparar e embasar a realização de APO. Acredita-se que a partir de das tecnologias existentes, incluindo os aplicativos indicados, seja possível elaborar uma matriz eficiente, uma plataforma digital, interativa e dinâmica, que auxilie uma avaliação focada na percepção dos usuários. Indicase que, posteriormente, para o desenvolvimento do projeto da matriz será necessário que a pesquisadora trabalhe em conjunto com programadores de aplicativos para dispositivos móveis.

Propondo uma metodologia eficiente para realizar a APO, através de uma matriz específica para avaliação das percepções dos usuários, que direcione os avaliadores durante a avaliação e possibilite a produção de material para apresentação dos resultados obtidos, espera-se facilitar esses processos estimulando que profissionais e estudantes de arquitetura e urbanismo enxerguem na Avaliação Pós-Ocupação uma atividade crítica, possível e necessária, além de um nicho a ser explorado no mercado brasileiro de construção civil.

\section{REFERÊNCIAS BIBLIOGRÁFICAS}

AIELLO-VAISBERG, T.M.J. Investigação de representações sociais. In: TRINCA, W. (org.) Formas de investigação clínica em Psicologia: procedimentos de desenhos de família com estórias. São Paulo: Vetor, 1997. p.267-268. 


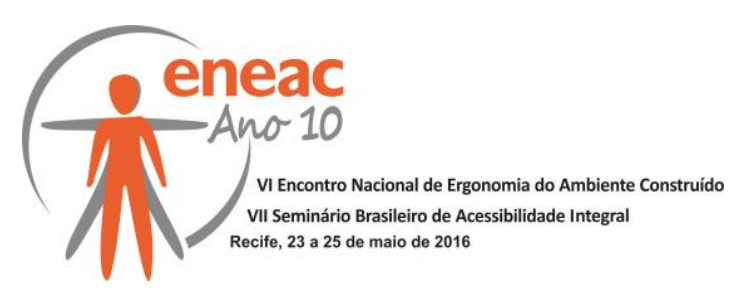

BARROS, L. A. F.; KOWALTOWSKI, D. C. C. K. Avaliação de projeto padrão de creche em conjuntos habitacionais de interesse social: 0 aspecto da implantação. São Paulo: NUTAU/FAU/USP, 2002.

BECHTEL, R. B. Avaliação Pós Ocupação. Manuscrito não publicado. Universidade do Arizona, Tucson, EUA, 1989.

BRASIL. Resolução no 6, de 24 de abril de 2007. Ministério da Educação, Fundo Nacional de Desenvolvimento da Educação. Disponível $<$ http://portal.mec.gov.br/arquivos/pdf/resolucao_n6_240407_proinfancia_medida18.pdf.pdf> Acesso em: 22 fev. 2015.

CAU. Resolução No 51. Brasília: CAU/BR, jun. 2013. Disponível em: <http://www.caubr.gov.br/wpcontent/uploads/2012/07/RES51-2013ATRIB-PRIVATIVAS20-RPO-1.pdf> Acesso em: 07 maio 2015.

ELALI, G. A. Ambientes para educação infantil: um quebra cabeça? Contribuição metodológica na Avaliação Pós-Ocupação de edificações e na elaboração de diretrizes para projetos arquitetônicos na área, São Paulo: USP, 2002.

FNDE. Fundo Nacional de Desenvolvimento da Educação, Ministério da Educação, Brasil. Programa Proinfância. Disponível em: <http://www.fnde.gov.br/programas/proinfancia> Acesso em: 25 maio 2015.

LYNCH, K. The Image of the City. Cambridge MA: MIT Press, 1960.

MARANS, R. W.; SPRECHELMEYER. Evaluating built environments: a behavioral approach. Ann Harbor, Michigan: The University of Michigan/Institute for Social Research and the College of Architecture and Urban Planning, 1987.

ORNSTEIN, S. Avaliação Pós-Ocupação (APO) do ambiente construído. Marcelo Roméro (colaborador). São Paulo: Studio Nobel, 1992.

PÁsCOA, O. N. F. A Qualidade do lugar em escola pública padronizada do Rio de Janeiro. Estudo de caso: Escola Municipal Tia Ciata. Rio de Janeiro: UFRJ, 2008.

PNE. Plano Nacional de Educação. Lei n. 13.005. Brasília, 2014. Disponível em: <http://www.planalto.gov.br/ccivil_03/_Ato2011-2014/2014/Lei/L13005.htm> Acesso em: 23 mar. 2015.

RHEINGANTZ, P. A.; AZEVEDO, G. A.; BRASILEIRO, A.; ALCANTARA, D.; QUEIROZ, M. Observando a qualidade do lugar: Procedimentos para a Avaliação Pós-Ocupação. Rio de Janeiro: PROARQ/FAU/UFRJ, 2009.

ROSSI, P. H.; FREEMAN, H. E. Evaluation - A Systematic Approach. Newbury Park, Sage Publications, 1989.

ROSSO, T. Racionalização da Construção. São Paulo: FAUUSP, 1980.

SANOFF, H. Visual research Methods in Design. Nova York: Van Nostrand Reinhold, 1991.

SOMMER, B.; SOMMER, R. A Practical Guide to Behavioral Research: Tools and Techniques. Nova York: Oxford University Press, 1997.

TCU. Tribunal de Contas da União. GRUPO I - CLASSE V - Plenário TC 011.441/2012-7. Relatório de Auditoria. Fundo Nacional do Desenvolvimento da Educação e Secretaria de Educação Básica do Ministério da Educação. Brasília, 2012. Disponível em: <http://portal3.tcu.gov.br/portal/page/portal/TCU/imprensa/noticias/noticias_arquivos/011.441-20127\%20\%28Proinf\%C3\%A2ncia\%29.pdf > Acesso em: 01 abr. 2015.

TRINCA, W. A investigação clínica da personalidade: o desenho livre como estímulo de apercepção temática. Belo Horizonte: Interlivros, 1976.

WORLDPANEL, K. Smartphone OS sales market share. Barcelona, 2015. Disponível em: <http://www.kantarworldpanel.com/global/smartphone-os-market-share> Acesso em: 21 nov. 2015. 